\title{
Using GIS and Mapping Tools to Access and Visualize Archival Records: Case Studies and Survey Results of North American Archivists and Historians
}

\author{
by Tom Belton
}

\begin{abstract}
Online map interfaces and GIS software are means of accessing and visualizing archival holdings associated strongly with places. This article investigates the possibility of an interest among at least some archivists and historians in finding records based on place names and maps. A review of recent tools and case studies on map-based methods of seeking and visualizing information in archives and special collections provides a current overview. A 2015 survey gathered additional information from archivists as to whether they place a high priority on, and are comfortable with, map-based methods, as well as to what extent their patron groups might benefit from such methods. A subsequent 2018 survey of historians provided evidence that this major patron group of archives would benefit from map-based methods of discovery, although the survey indicated that they are focused on GIS software, not simple visualization tools, in their own work. The literature and survey data validate the premise that many archives patrons are interested in exploring this area, but that the difference between archivists' and historians' technical knowledge and interests is a significant obstacle.
\end{abstract}

\section{Introduction}

Place and time are two paramount concepts in archives. Individuals and organizations accumulate archives over time, and virtually all documents can be associated with multiple places and dates; moreover, this metadata is an important part of archival description. However, archival description systems are still largely limited to text-based methods of allowing users to conduct searches. In the meantime, information seeking on the web in general has moved beyond plain text searching to increasingly graphic ways of browsing and locating information.

Geographic information software (GIS) has become sophisticated over the last several decades. GIS comprises a range of software enabling geographic data manipulation and presentation using graphic mapping layers. Several very powerful proprietary and open source tools, such as ArcGIS and Quantum GIS (QGIS), have evolved to meet a variety of academic and corporate needs. These applications provide the full range of functionality for managing geographic information, both on the desktop and via the web. The strength of these programs is their ability to combine maps and data in flexible and complex ways. Geographers and other social scientists use both programs widely to create map layers of their research data. The major difference between the two is that ArcGIS is proprietary and QGIS is open source. ${ }^{1}$ At the same time, relatively simple 
web-based map tools, such as Google Maps and OpenStreetMap, have become increasingly popular with nonspecialist audiences. Consequently, more and more searchers online are finding up-to-date information about the environment, public institutions, businesses, cultural and tourist attractions, and so on using map interfaces. Moreover, these products often form the mapping layers for heritage-oriented web services such as Historypin, Viewshare, and VisualEyes. Individuals and organizations can use these tools to affix historic photographs and text to maps and timelines. Cultural heritage institutions such as archives have made some use of these services in the last several years; in other cases, such organizations have built their own interfaces.

As using map interfaces to access and visualize archival holdings associated with places grows in importance, so too does the question of archivists' priorities on the use of, and comfort-level with, map-based methods. To address this issue, the author conducted a survey in 2015, assessing archivists' attitudes toward these technologies, as well as their opinions on the extent to which patron groups may benefit from such methodologies. In 2018, to obtain direct evidence of the latter, the author developed a second survey of historians to focus on a single, very important, patron group. To inform the surveys, the author undertook a review of visualization tools, as well as several published and other case studies of their uses.

\section{Literature Review of Visualization Tools}

Many locally developed and open source tools, including products such as Viewshare, ${ }^{2}$ VisualEyes, Historypin, and Flickr, link information objects to geographic coordinates, but their sophistication and comprehensiveness varies. The Library of Congress developed Viewshare to help memory institutions share their collections in visual ways, including maps; it made an impact in the literature after its inception in 2011 but was retired in $2018 .{ }^{3}$ Several Viewshare projects utilizing archival or other primary source content are described in the literature review.

The University of Virginia developed VisualEyes with similar goals in mind. Like Viewshare, VisualEyes requires a map to link with an associated spreadsheet of metadata, which must include latitude and longitude for the map to function properly. ${ }^{4}$ Unlike Viewshare, VisualEyes is intended for use by digital humanities scholars, not cultural institutions.

Flickr began in 2004 as an online photo sharing and organizing tool; it uses OpenStreetMap data for its mapping component. ${ }^{5}$ Flickr treats geographic coordinates as one among many details of metadata kept on its vast photographic collections; many public institutions share their rich holdings at Flickr Commons, which is searchable via a world map. ${ }^{6}$

Historypin began in the United Kingdom in 2010 as a tool for community groups and institutions to share local history content using a map interface and timelines. ${ }^{7}$ Its ease of use in associating collection content with map locations initially attracted a large number of memory institutions. "Pinning" documents on a Google Maps interface such 
as Historypin is straightforward and does not require explicit geocoding; however, bulk uploading of pins without the use of the map requires location references to be included in the metadata for the documents.

A seminal study on visual search options, "Visual Information Seeking: Tight Coupling of Dynamic Query Filters with Starfield Displays," published shortly after the introduction of the World Wide Web in 1993, highlighted the importance of both the visual representation of the world of action (e.g., the use of knobs, sliders, and buttons on web pages) and the information seeker seeing as much of the information universe as possible (defined as the "starfield display"). ${ }^{8}$ Many studies of visualization and visual searching refer explicitly to this study and build upon its recommendations.

Recent scholars point to the importance of using visualization and visual search tools to improve awareness of, and access to, digital collections. For instance, in "Generous Interfaces for Digital Cultural Collections," Mitchell Whitelaw contends that the search box is limiting and argues for greater "generosity" in the creation of "rich, browsable, interfaces for large, real-world digital collections." In the subsequently described case studies, Whitelaw's generous browsable interfaces serve as both exhibitions and catalogs of several projects focusing on photographs and other images. ${ }^{10}$

A departure point for more detailed literature analysis is the extent to which archival patrons have traditionally sought place-based information, regardless of the presence of a map interface to do so. For example, the 2011 paper "Linking Archival Data to Location: A Case Study at the UK National Archives" outlines an initiative to gather and standardize place-based information for England and Wales. ${ }^{11}$ In 2009, an archives' in-house study found that $20 \%$ of 3,000 queries to its online catalog were place based, the second most frequent type of search. ${ }^{12}$ The writers go on to explain how this assessment was put to work in building initial prototypes of map-based search tools for certain record sets. Building such a prototype necessitated the georeferencing (i.e., the formal linking of an object to its exact geographic coordinates on Earth's surface) of certain data sets held by the National Archives. ${ }^{13}$ Georeferencing is an important facet of the process of building functional map tools.

Other studies reinforce the importance of place-based information and mapping layers as ways of meeting patron needs. For instance, Deborah Boyer outlines a 2005 project to improve access to historic photographs at the Philadelphia Department of Records using a custom-built online map interface. ${ }^{14}$ Boyer gives the following rationale for the project:

The DOR [Department of Records] felt that this connection to place would resonate with potential users of the site. People connect strongly with the built environment, and historic photographs can trigger memories for many individuals. Because Philadelphia has long been known as a city of neighborhoods, the DOR reasoned that people would want to locate images based on geographic criteria such as address, intersection, or neighborhood..$^{15}$ 
The Philadelphia Department of Records had to build its map interface ${ }^{16}$ from scratch using the resources of a local GIS software company. ${ }^{17}$ Since that time, additional collaborative tools with similar interfaces have emerged: Historypin, Viewshare, VisualEyes, and other visualization tools with mapping components. Archival photographs and additional graphic records are popular subjects of this sort of treatment as they are heavily used and are often easily associated with places. These third-party tools obviate the need for extensive in-house technical development, unless a very specialized purpose is required.

In 2012, Jefferson Bailey and Trevor Owens outlined the development of Viewshare via the Library of Congress/National Digital Information and Infrastructure Preservation (NDIIP) program and how the Brooklyn Public Library used it to improve access to its Fulton Street Trade Card Collection. ${ }^{18}$ The Fulton Street exhibit site provides map-based access to a digitized collection of local business advertisements from a major street in Brooklyn, New York. It is easy to imagine how one might apply this approach to other digital collections that are clearly place based, such as maps, postcards, photographs, and certain textual records. The authors emphasize that Viewshare does not require extensive technical knowledge or resources. ${ }^{19}$

To reiterate, this evolving preference for place in archival information seeking and mapping layers found in tools such as Viewshare is part of the much larger development of the visualization of cultural resources. Many available software products provide more functionality than georeferencing and map making. For example, Viewshare offered the ability to visualize archival collections as timelines, image galleries, and tag clouds. ${ }^{20}$

Laura Deal describes an initiative by the Wilson Center Library in Washington, DC, to provide map-based access to a collection of Cold War-related documents. Deal offers the same critique of text-based access to collections as many of the previously noted authors. She too places this critique in relation to the data visualization movement, which is only beginning to make inroads in libraries and archives. In her use case, Deal points to the importance of geographical access to these documents in relation to their subject matter as opposed to their places of origin. Her study ends with a tutorial on using Viewshare to create visualizations other than maps. ${ }^{21}$

Similar results emerge from other case studies and tools. Craig Harkema and Catherine Nygren's 2012 paper points out that Historypin is a useful tool that does not require an extensive injection of archival resources other than the time to upload images and associated metadata. However, they conclude that Historypin should only be a supplementary tool, as it offers little opportunity for customization of, and control over, the functionality of third-party software. Their university library is more likely to invest resources in open source content management platforms such as Islandora where local customization is easier to arrange. ${ }^{22}$

Another excellent example of a project built specifically to anticipate patron interest in high demand series or collections is the National Archives of Australia's "Discovering 
[formerly Mapping Our] Anzacs" site, ${ }^{23}$ which provides map-based access using Google Maps to Boer War and World War I service records from Australia and New Zealand (see Figure 1).

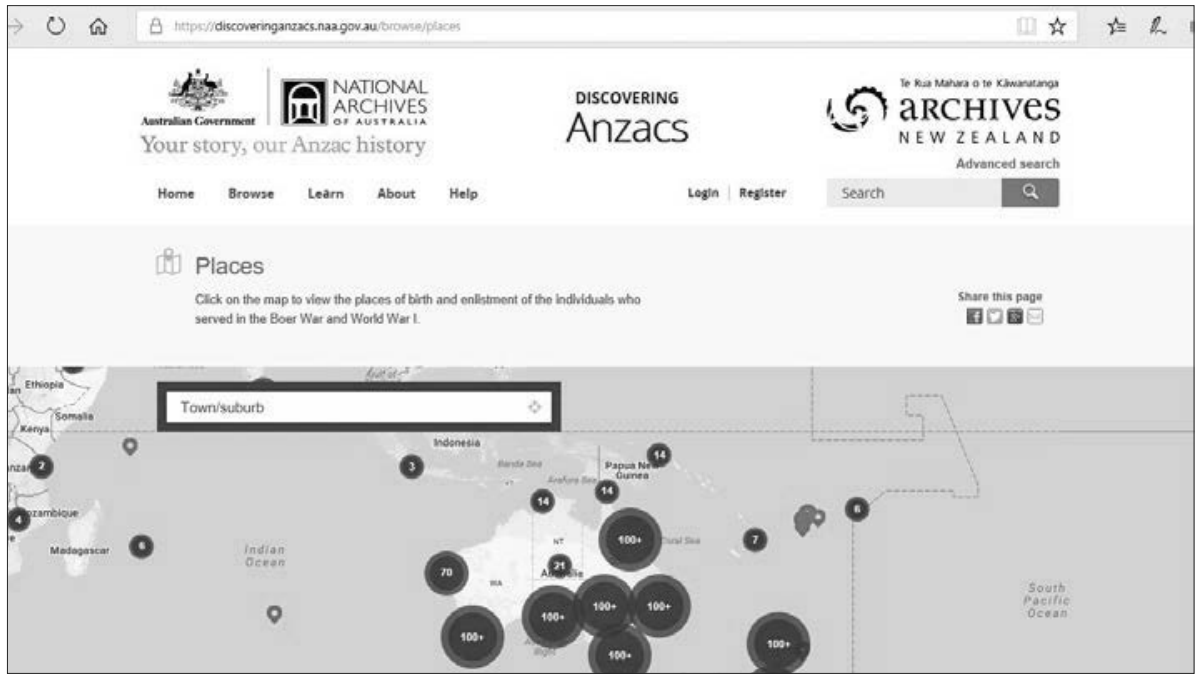

Figure 1: "Discovering Anzacs," National Archives of Australia, http://discoveringanzacs.naa.gov.au/ browse/places

This site was built on the assumption that a "spatial pathway into records would make sense for local communities where, in many cases, a World War I memorial is central to the town and the community." ${ }^{24}$ To create the site, staff extracted and restructured place-based information from the archives' main online catalog. The current iteration of the site allows users to search places using a text box or to browse a world map interface to locate service records associated with particular birthplaces and enlistment locations of soldiers. ${ }^{25}$

"Discovering Anzacs" raises the issue that a given archival record could be associated with more than one place. This is an important matter when it comes to the decision as to where the archival document is located on the map interface. For instance, the military service records are associated with birthplaces and places of enlistment. "Discovering Anzacs" handles this issue by showing the same service record in both locations.

The last case study example describes the more unusual idea of using a map layer on archival descriptive catalogs or finding aids. Most maps found on archives websites, or tools like Historypin, provide direct access to digitized copies of records (such as photographs) along with some metadata. Maps that provide access to descriptions or finding aids are rare. ${ }^{26}$ The website of the Dalhousie University Archives in Halifax, Nova Scotia, created one. ${ }^{27}$ This map layer (see Figure 2) functions alongside the more 
conventional search and browse options found on the left-hand side of the screen. ${ }^{28}$ The public descriptions site runs off the AtoM open source description software. Dalhousie added the map layer using ArcGIS. The archives leveraged the place-based access points built into AtoM to create its map.

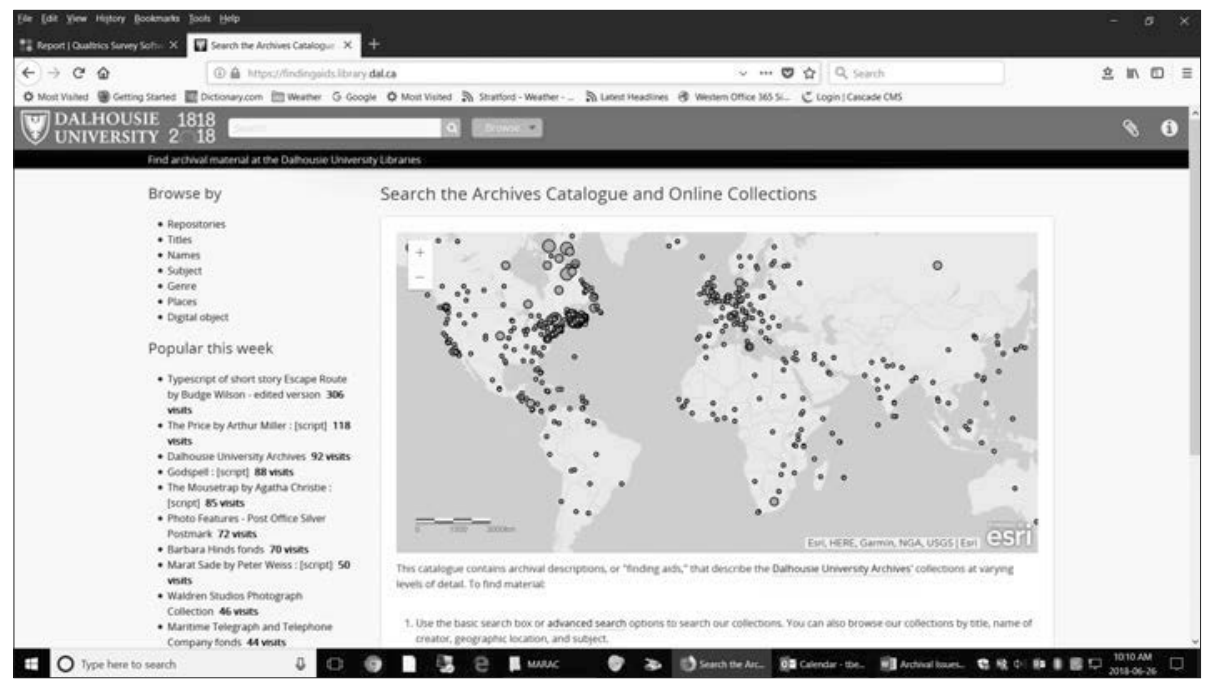

Figure 2: Dalhousie University, Search the Archives Catalogue and Online Collections, https:// findingaids.library.dal.ca

Dalhousie Archives staff recently completed a project embedding latitude and longitude codes within the AtoM software so that the map can be updated more easily. Because the location codes are based on place names, they will not be as precise as they could be (i.e., not down to the level of a specific address), but they will be adequate for the vast majority of archival descriptions. Archives staff will periodically export geographic data such as this to update the ArcGIS map layer. Some of this place data, not currently including location coordinates, could be exported to other institutions. Furthermore, the work undertaken at Dalhousie on its archives discovery layer could serve as a model, particularly for the many Canadian archives and networks running the AtoM software.

\section{Discussion}

Another issue arises from these case studies. Geocoding and mapping archives are not simply one activity but rather a series of at least three interconnected activities, the first two of which are particularly labor intensive: 1) standardizing a georeference (e.g., the latitude and longitude of a place) and/or place names over time; 2) embedding and encoding these georeferences in archival descriptive records; and 3) installing mapping layers on archives catalogs or sites. Archivists have made progress in standards and techniques for geocoding in archival description; for example, "geographic coordinates" 
is a relatively new addition to the "geographic name" element in the Encoded Archival Description tag library. ${ }^{29} \mathrm{~A}$ challenge in implementing georeferencing relates to the presence of historic place name data that may be difficult to associate with current locales. This is similar to the challenge of identifying predecessor and successor names in agency authority records. However, the addition of mapping layers to data is quite feasible if geographic coordinates are present in the record. One can obtain precise coordinates for current locations from tools such as Google Maps.

This overview suggests that a sizable number of online users of archives would benefit from map-based access to holdings and that several simple tools are available to that end. Additionally, the case study literature reveals that a number of archival institutions and libraries have investigated the issue and built prototypes and add-ons, or used a web service, to support this need. The desire for place-based access to archival holdings likely will not diminish, and may increase, as tools such as Google Maps are applied to more and more information objects, and as visualization of online information becomes more commonplace. To what extent do archival communities support the idea and have the skills and resources to implement mapping layers on a larger scale? To address this question, the author surveyed archivists in North America to determine their level of interest and their resources.

\section{Archivist Survey Methodology}

In early 2015, the author received ethics approval to conduct a survey of North American archivists and special collections librarians. The survey was available between May 15 and June 12, 2015, via announcements on the Canadian and American archives listservs Arcan-L (sponsored by the Canadian Council of Archives) and Archives and Archivists (sponsored by the Society of American Archivists). ${ }^{30}$ During the survey period, 60 responses were received. This was a limited response, which may indicate a lack of broad professional interest in the topic. On the other hand, a greater response may have been received had the survey been targeted, for instance, at an SAA subgroup focused on metadata, access, and discovery, or on visualization tools.

\section{Findings}

The first consideration was whether an archives had an online catalog or exhibit that provided access through a map interface. Second, regardless of whether the institution had a map interface, to what extent did respondents feel their patrons would benefit from such a thing? Additionally, questions were asked about the tools being used, what content was being mapped, and what obstacles were in the way to providing such a service. The survey consisted of 10 questions that related to these issues and gauged the interest and expertise among archivists in the use of mapping layers to provide visualization of, or access to, archival resources. The full survey may be found in Appendix A. 
1. What type of archival or special collections institution do you represent?

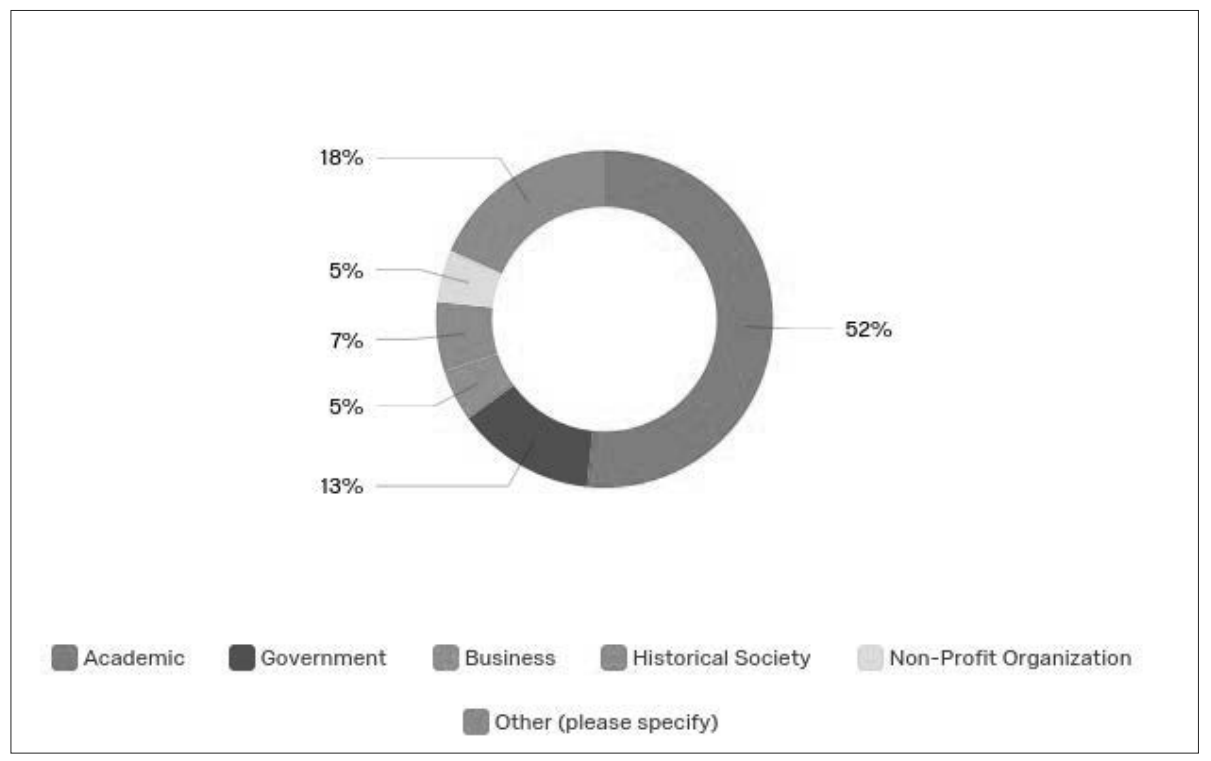

Figure 3: Type of archival or special collections institution $(\mathrm{n}=60)$

Just over half (52\%) of the 60 respondents worked at academic archives and/or special collections. The next largest number was other (18\%), which primarily included public libraries. Government archives (13\%), followed by historical societies (7\%) and business archives (5\%), were the next largest groups. ${ }^{31}$

2. Does your institution's online catalog, descriptive database, or finding aid repository provide access to archival descriptions and/or digital objects (e.g., photographs) through a map interface?

This question focused on the core discovery components of archives and special collections libraries. Thirteen respondents answered "Yes" to this question (22\%), and 47 answered "No" (78\%).

3. Does your archives website provide any online visualizations of digital objects (e.g., exhibits of photographs or other graphic materials) via a map interface?

A slightly higher percentage (24\%) of respondents answered "Yes" to this question, and $76 \%$ answered "No." The results compare very well with the previous question, although it is much easier to use tools such as Historypin to map digital objects than to build such functionality into an archival database management or library cataloging system. For this reason, an even higher number of affirmative answers to this question might have been expected. Respondents may have assumed that third-party sites such as Historypin do not constitute a part of their institutions' own websites. 
4. Regardless of how you answered question 3, to what extent do you think that your patrons benefit, or would benefit, from being able to visualize your holdings and/or search online catalogs or finding aids using a map interface? Check one.

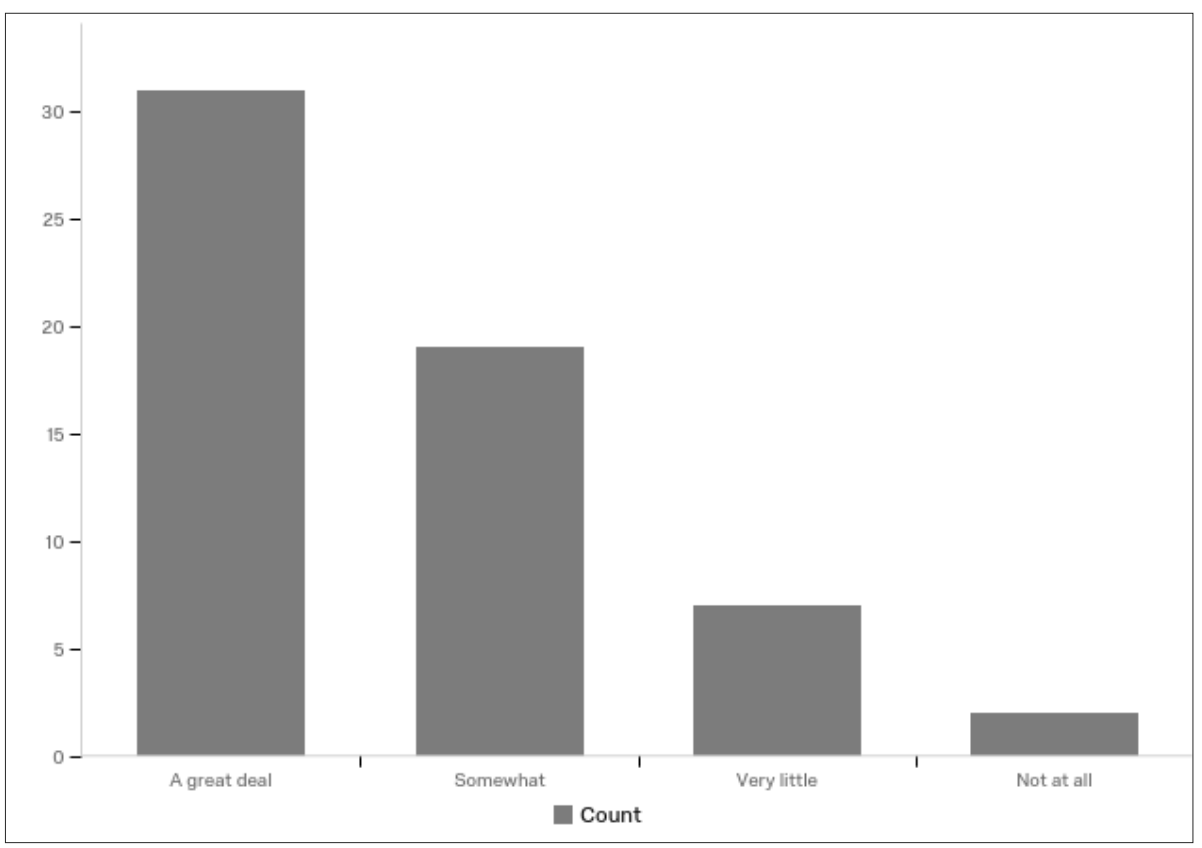

Figure 4: Benefit to patrons of map interfaces $(\mathrm{n}=59)$

Possible answers were a great deal, somewhat, very little, not at all. No numerical scale was included. Fifty out of fifty-nine respondents (85\%) to this question answered either "a great deal" or "somewhat." Specifically, 53\% felt that their patrons would benefit a great deal. 
5. Please identify which of your actual or potential patron groups that benefit, or would benefit, from being able to visualize your holdings and/or search online catalogs or finding aids using a map interface.

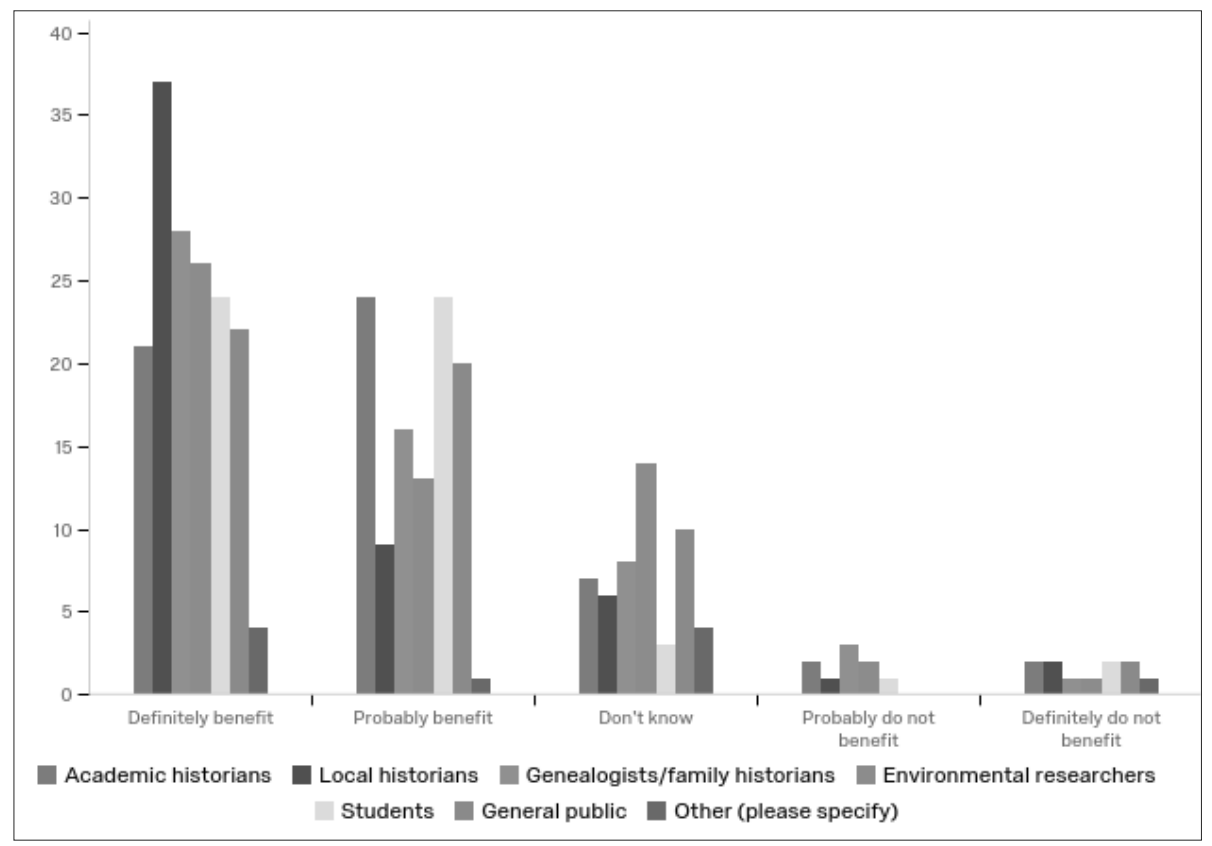

Figure 5: Patrons who would benefit from map interfaces $(\mathrm{n}=56)$

Possible answers were academic historians, local historians, genealogists/family historians, environmental researchers, students, general public, or other (please specify). In each case, respondents were asked to rank each group from 1 (definitely benefit) to 5 (definitely do not benefit).

Fifty-six respondents submitted 341 separate ranks; of these, only twenty (6\%) were "do/would not benefit." A total of 269 ranks were "do/would benefit." Therefore, the overall mean response to this question was 1.88 (closest to rank 2, "probably benefit"). The highest mean response (1.58) was in relation to local historians. 
6. What are the main reasons that your institution does not provide visualizations of digital content via a map interface? Check all that apply.

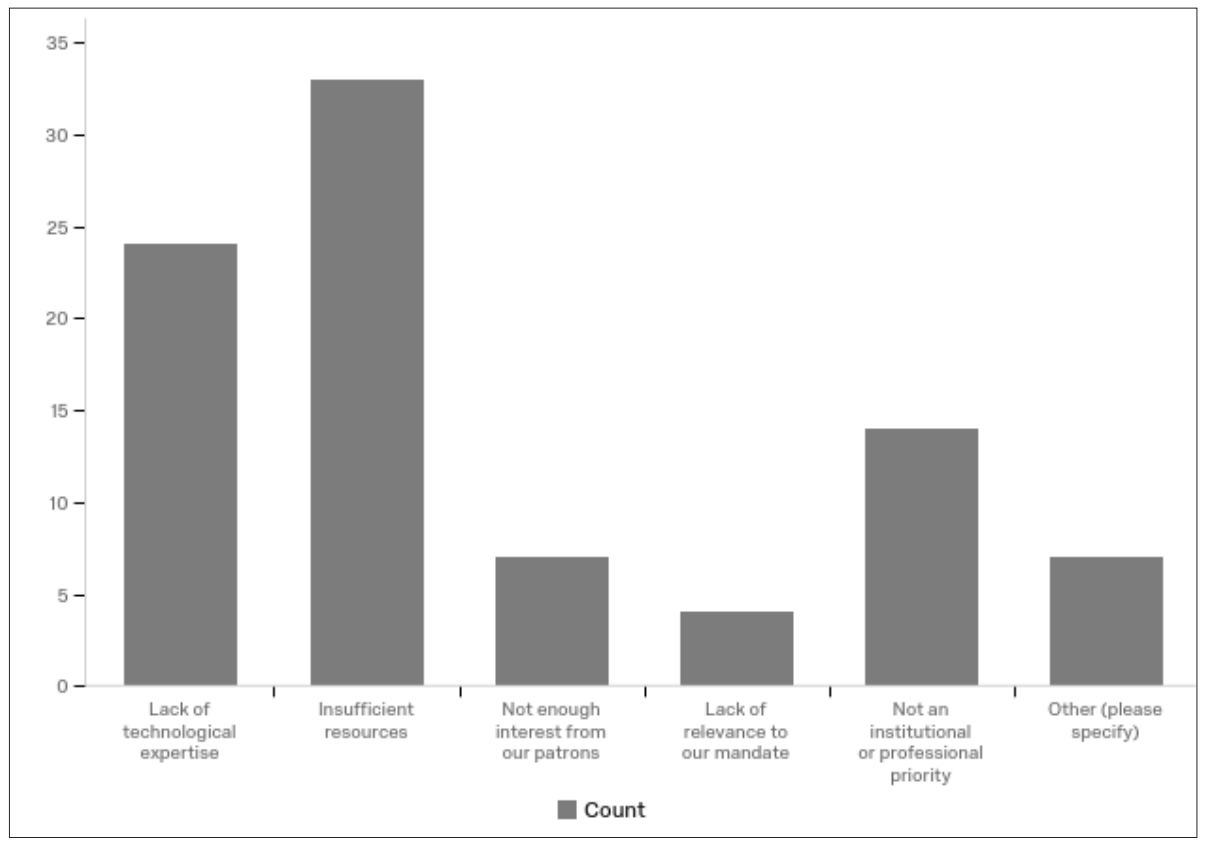

Figure 6: Reasons for not using map interfaces $(\mathrm{n}=43)$

This question was only visible to those who answered "No" to questions 2 and 3. Possible responses were lack of technological expertise, insufficient resources, not enough interest from our patrons, lack of relevance to our mandate, not an institutional or professional priority, or other (please specify).

The 43 respondents to this question represent virtually all who answered "No" to questions 2 and 3. (Not everyone who responded "No" to question 2 answered this question.) Respondents could give multiple answers to this question. They gave 89 reasons, 57 of which were either lack of technological expertise or insufficient resources. The remaining 32 answers were not an institutional or professional priority (14), not enough interest from our patrons (7), lack of relevance to our mandate (4), and other (7). Most of the "other" responses were similar but just worded differently.

Only those 13 or 14 individuals who responded "Yes" to questions 2 and 3 answered questions 7 through 10. 
7. What tools or web services are you using to visualize digital objects via a map interface? Check all that apply.

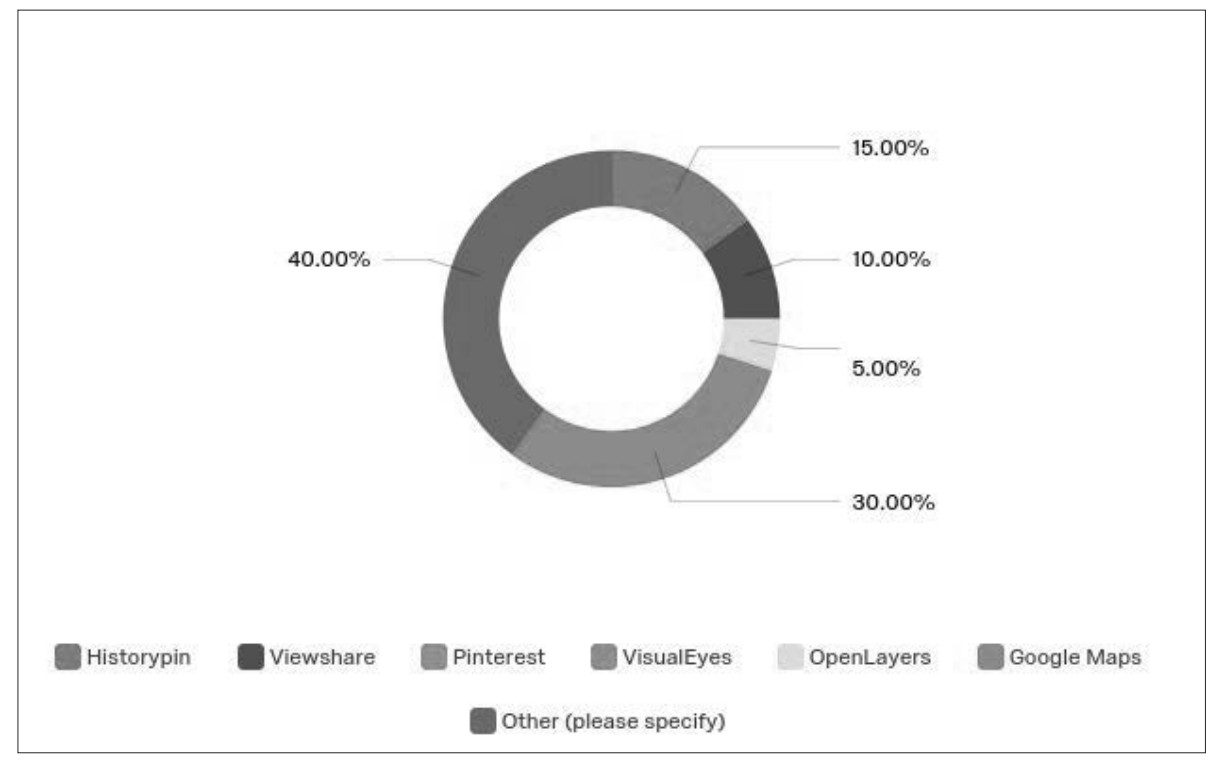

Figure 7: Tools and web services being used ( $\mathrm{n}=12)$

Possible choices were Historypin, Viewshare, Pinterest, VisualEyes, OpenLayers, Google Maps, and other (please specify). Twelve respondents gave 20 responses, with Google Maps (6 responses) and Historypin (3) as the most commonly used of the tools from the list. However, almost half (8) of the responses were "other." Around half of these referred to other freely available tools (e.g., Flickr, Google Earth) and the other half to in-house and custom tools. No respondents referred explicitly to GIS software in their "other" responses. 
8. What sort of digital objects predominate in your map interface? Check all that apply.

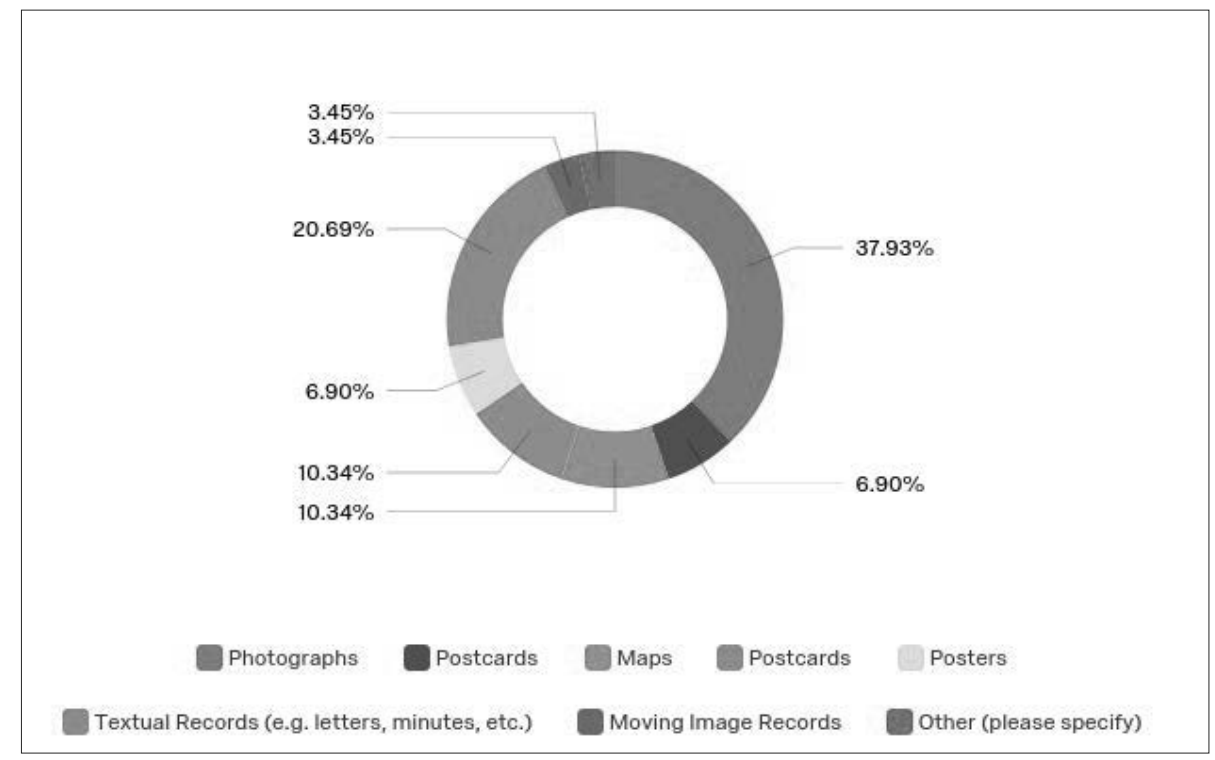

Figure 8: Sorts of digital objects in map interfaces ( $\mathrm{n}=12)$. The survey mistakenly included the "postcards" category twice. The percentages between the "postcards" categories differ because 2 responses out of 29 were for the first "postcards" in the list (6.9\%), and 3 were for the second (10.34\%). In reality, the total for "postcards" is 5 (17.24\%), but it isn't possible to reflect this on the graph without merging the underlying. data.

Possible choices were photographs, posters, maps, postcards, textual records, moving image records, or other (please specify). Twelve respondents provided twenty-nine responses. While almost all (11 responses) mentioned photographs, textual records (6) also ranked high, especially compared to other materials (e.g., postcards and maps) that one might assume would lend themselves more to mapping and visualization. 
9. What is the primary purpose of these online map interfaces for your institution?

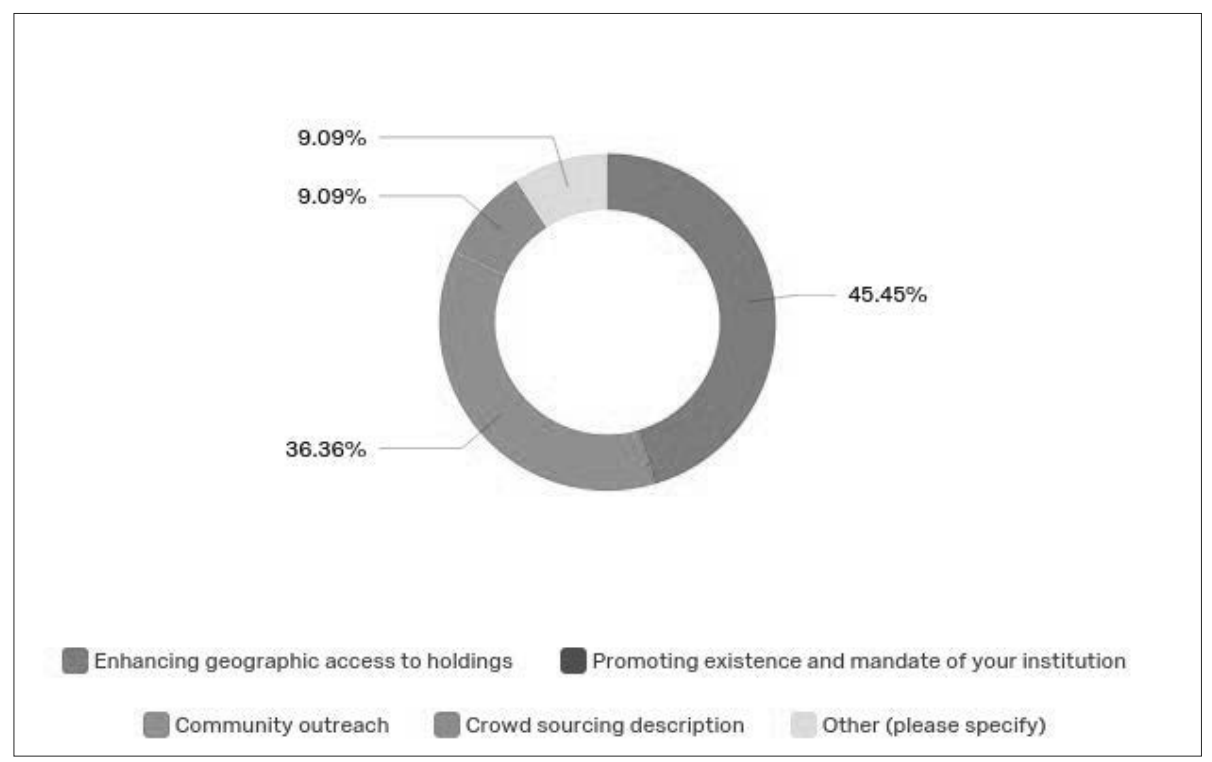

Figure 9: Primary purpose of map interfaces (n = 11)

Respondents had to select one response each. Possible responses were enhancing geographic access to holdings, promoting existence and mandate of your institution, community outreach, crowdsourcing description, and other (please specify). Eleven respondents gave that number of responses, the vast majority of which (9) were either enhancing geographic access to holdings or community outreach.

10. Please make any additional comments that you feel are relevant.

Responses here provided elaborations of projects undertaken and tools not noted in the survey. Unsurprisingly, these comments were generally supportive of the idea of searching and browsing collections using a map interface. For example, one respondent wrote, "Our website is still in development, but there is no question that map-based access will be a significant feature." Another commented that "We have long felt that developing a map interface that includes a time element would increase our very entry level researchers' ability to gain access to the information they are looking for in more productive swaths. As a geographically bounded collecting institution, a map/time based interface would allow us to rapidly identify blindspots and gaps in our collections, e.g., 'we have nothing on this particular town/creek/business between 1940-1990.” 


\section{Archivist Survey Discussion}

It would appear that most archivists on the listservs work in academic archives/special collections, as the response rate from them was higher. The survey makes clear that three-quarters of respondents do not provide any form of map interface to their resources or finding aids. Given the literature reviewed, and the reality that few, if any, library or archival cataloging systems have mapping layers, it is not surprising that few institutions would provide such a service.

Clearly, barriers exist to extensive implementation of map-based tools and methods of access. The main ones (lack of expertise and resources) are not surprising given the small sizes and budgets of many archives. However, these obstacles relate to a perceived or actual lack of capacity to provide map-based interfaces, not to a lack of interest.

Despite the relatively low number of "Yes" responses to questions 2 and 3, solid evidence exists that respondents felt strongly about the benefits to users of providing access to records using a mapping layer. Indeed, 85 percent of the respondents felt their patrons would benefit a great deal or somewhat from visual tools such as map interfaces. This reinforced the literature findings that place-based information is key to a considerable number of archives users and that maps usage has become an important means of seeking this information. Furthermore, the answers to question 5 point to community-based researchers as being most interested in the documentation of places.

Direct corroboration from archival patrons was missing from the survey, however. To gather evidence from a significant group of such users, the author conducted a survey of North American historians in early 2018.

\section{Survey of Historians}

The survey was available during the month of March 2018. The author announced it via the American Historical Association website and through a targeted social media posting in Canada. During the survey period, out of 53 questionnaires opened, 37 complete responses were received. The overall focus of the survey was to analyze historians' methodology with respect to primary sources and research data.

\section{Findings}

The results could inform research in a number of areas. For purposes of this article, however, the intent was to ascertain whether the respondents felt strongly that map interfaces are a useful way to visualize both primary sources and their own research data and outputs. Therefore, only those questions pertaining to respondents, primary sources, and geospatial information are analyzed here. The full survey may be found in Appendix B.

1. Please identify your discipline. 
While the survey focused primarily on historians, historical geographers were also encouraged to respond. In the end, however, the vast majority of respondents (33) were historians, compared to two historical geographers. ${ }^{32}$

2. What types of primary sources (i.e., usually created at the time under study) do you use in your research? Select all that apply.

Respondents could select more than one answer. The most popular responses to this question were newspapers and books and textual records (both 35), maps (33), and photographic records (28), with other categories trailing well behind.

3. How important is place-based or geospatial information to your research or teaching?

This question was presented as a three-item Likert scale. Of 36 respondents, 18 rated place-based information as crucial to their research and teaching. Of these, 15 historians rated geospatial information as crucial. A further 15 overall respondents ranked place-based information as important.

4. What types of geospatial information are important to your research or teaching?

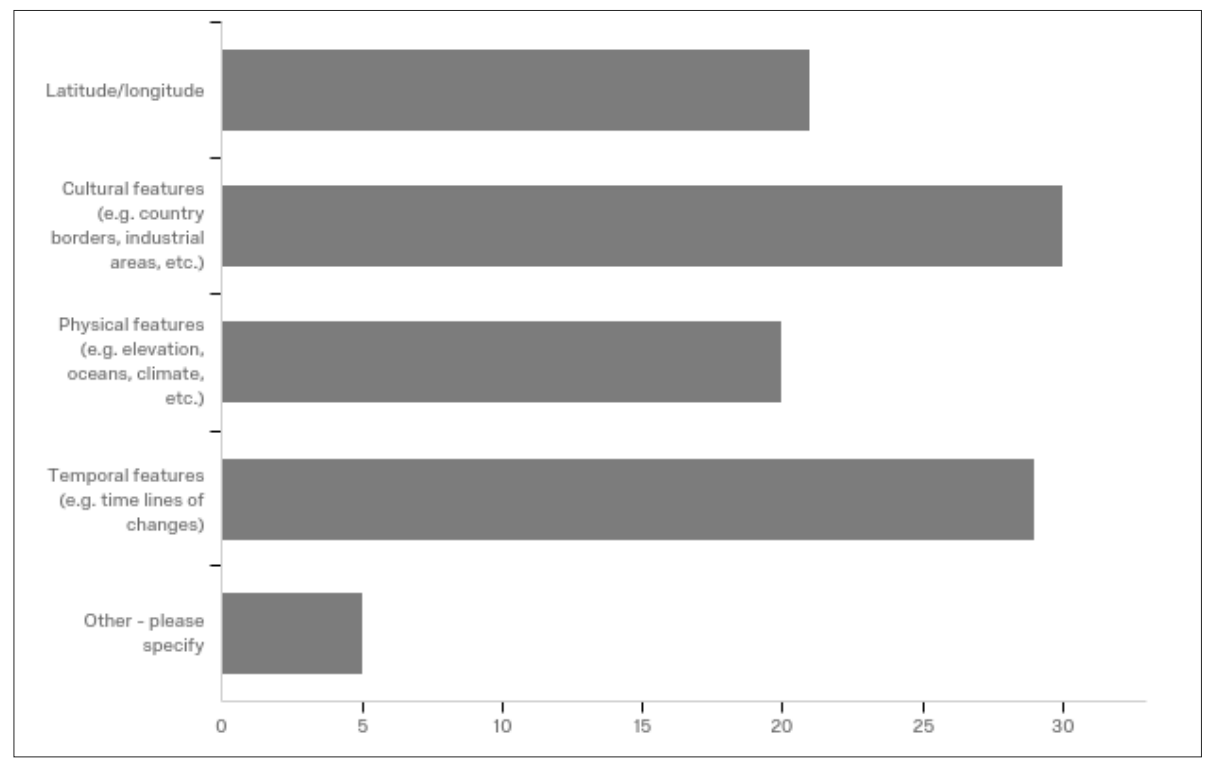

Figure 10: Types of geospatial information that are important for research and teaching $(\mathrm{n}=35)$

Twenty-one respondents, including nineteen historians, ranked latitude/longitude as important geospatial information for their research. However, more respondents (30 and 28 , respectively) ranked cultural features, such as national borders, and temporal features, such as timelines, as important. 
5. In what way(s) do you, or would you like to, use geographic information or mapping software to capture and/or visualize data? Select all that apply.

\begin{tabular}{|c|c|c|c|}
\hline \# & AWA.FIELD & SIMPLETABLEWIDGET.C & CHOICE_COUNT \\
\hline 1 & To document sources in archives, libraries, or museums & $14.55 \%$ & 16 \\
\hline 2 & To visualize your own research data or outputs & $27.27 \%$ & 30 \\
\hline 3 & To integrate maps and time lines & $25.45 \%$ & 28 \\
\hline 4 & To place historical narratives in a spatial context & $29.09 \%$ & 32 \\
\hline 5 & Not interested in geographic information software & $0.91 \%$ & 1 \\
\hline \multirow[t]{3}{*}{6} & Other - please specify & $2.73 \%$ & 3 \\
\hline & & & 110 \\
\hline & SIMPLETABLEWIDGET.SHOWING_ROWS_OF & & \\
\hline
\end{tabular}

Figure 11: Ways to use GIS or mapping software to capture or visualize data (n = 36)

Respondents could select multiple choices. Most respondents felt strongly about the use of mapping tools for their own practice: 32 use them to place historical narratives in a spatial context, 30 use them to visualize their own research data or outputs, and 28 use them to integrate maps and timelines. Less common is for respondents to document sources in archives, libraries, and museums: only 16 respondents do this, or would like to.

6. Which of the following GIS software or mapping tools have you used?

\begin{tabular}{|c|c|c|c|}
\hline \# & & AWA.FIELD & SIMPLETABLEWIDGET.CHOICE_COUNT \\
\hline 1 & ArcGIS & & $22.12 \% \quad 23$ \\
\hline 2 & QGIS & & $14.42 \% \quad 15$ \\
\hline 3 & Visual Eyes & & $0.96 \% 1$ \\
\hline 4 & Viewshare (Library of Congress) & & $2.88 \% 3$ \\
\hline 5 & WorldMap (Harvard) & & $3.85 \% 4$ \\
\hline 6 & Google Maps & & $28.85 \% \quad 30$ \\
\hline 7 & OpenStreetMaps & & $10.58 \% \quad 11$ \\
\hline 8 & Historypin & & $3.85 \% 4$ \\
\hline 9 & Don't use GIS or mapping tools & & $1.92 \% 2$ \\
\hline \multirow[t]{3}{*}{10} & Other - please specify & & $10.58 \% \quad 11$ \\
\hline & & & 104 \\
\hline & & SIMPLETABLEWIDGET.SHOWING_ROWS_OF & \\
\hline
\end{tabular}

Figure 12: GIS or mapping tools being used ( $\mathrm{n}=36$ ) 
Most respondents are familiar with more sophisticated GIS tools such as ArcGIS (23 respondents) and QGIS (15). The vast majority have used, or would use, a well-known tool such as Google Maps. However, only a handful are familiar with simpler visualization tools such as Historypin (4), Viewshare (3), and VisualEyes (1).

7. What primary sources would lend themselves to discovery via an online map interface?

\begin{tabular}{|c|c|c|c|}
\hline \# & & AWA.FIELD & SIMPLETABLEWIDGET.CHOICE_COUNT \\
\hline 1 & Correspondence & & $13.30 \% \quad 25$ \\
\hline 2 & Audiovisual records & & $9.04 \% \quad 17$ \\
\hline 3 & Personal diaries & & $12.77 \% \quad 24$ \\
\hline 4 & Newspapers & & $12.23 \% \quad 23$ \\
\hline 5 & Maps & & $15.96 \% 30$ \\
\hline 6 & Photographs & & $15.96 \% 30$ \\
\hline 7 & Travel accounts & & $15.43 \% \quad 29$ \\
\hline 8 & Websites & & $3.19 \% 6$ \\
\hline \multirow[t]{3}{*}{9} & Other - please specify & & $2.13 \% 4$ \\
\hline & & & 188 \\
\hline & & SIMPLETABLEWIDGET.SHOWING_ROWS_OF & \\
\hline
\end{tabular}

Figure 13: Primary sources that lend themselves to discovery via a map interface $(\mathrm{n}=33)$

The respondents identified a total of 188 types of primary source materials that would lend themselves to an online map interface. Of these 188, the top responses were photographs and maps (30 each), travel accounts (29), correspondence (25), personal diaries (24), and newspapers (23).

The remaining survey questions dealt with research methodology and data management, not including reference to mapping tools or GIS software.

\section{Historian Survey Discussion}

The results reveal that historians are very interested in geospatial information, the interplay between place and time, and their visualization in online mapping tools. The vast majority of the 37 respondents, 35 of whom were historians, rated place-based or geospatial information as important or crucial to their work. More unexpected is that so many historians (as opposed to historical geographers) are quite familiar with GIS software tools such as ArcGIS (21 responses) and QGIS (13). In fact, these historians are much more familiar with GIS software than they are with simple visualization tools such as Historypin (4 responses) or Viewshare (3). Perhaps GIS-savvy historians were more inclined to complete this survey, but, regardless, a significant percentage of the profession is familiar with sophisticated mapping software. The survey also reveals that historians see primary sources of the sorts found in archives as highly "mappable." 
However, only about half of historians in the survey are actually interested in, or have the time for, doing this because they are focused on using GIS software to document their research data and results. Relatively few of them are using simpler tools such as Historypin. This leaves an opportunity for archivists to fill a gap by using either these simple tools, or GIS software if they have access to it, to document archival sources that lend themselves to online mapping, focusing on those sources that historians themselves have identified as important or crucial to their work. Historians feel strongly about mapping and visualization of textual sources such as correspondence, travel accounts, and personal diaries, not just photographs and maps. They are concerned not only with latitude and longitude but also with cultural and physical data that could be mapped. Archivists should take these preferences very seriously when using either simple tools such as Historypin or programs such as ArcGIS.

\section{Conclusion}

Challenges such as lack of resources and training for archivists to develop in this new area are ongoing. Clearly, barriers exist to extensive implementation of map-based tools and methods of access. The main ones (lack of expertise and resources) are not surprising given the small sizes and budgets of many archives.

However, the clear majority of the respondents to the archivist survey feel their patrons would benefit a great deal or somewhat from visual tools such as map interfaces. This reinforces the literature findings that place-based information is key to a considerable number of archival users and that the use of maps has become an important means of seeking this information. The survey of historians strengthens the argument that both place-based information and mapping functionality are very important to a major archival patron group. Both archivists and historians are aware of the importance of the visualization of records to enhance their utility as sources of historical knowledge.

To the extent that archives use mapping tools, most items in use are photographs and other graphic materials. Not surprisingly, visualization tools favor the inclusion of more graphically striking materials, but historians are not necessarily looking for this. They would like to see rich textual resources such as correspondence and newspapers as much as anything else. Most of the tools archivists use are relatively simple ones such as Historypin, Viewshare, and Flickr as well as mapping layers from Google Maps and OpenLayers. A few institutions with the resources and expertise, such as the City of Philadelphia Department of Records and Dalhousie University Archives, have used at least some of the features of GIS software.

Regardless of whether basic or advanced tools are used, digitization and upload of archival resources and associated metadata requires a refocusing of work processes. Not all resources need to be mapped, but, when they are, the work can be integrated into other metadata or access processes. Pinning items to a map one at a time is straightforward and may serve the needs of community engagement, but this approach is not highly productive as a means of providing broad access to holdings. 
Moreover, the survey of historians reveals that they are not using such basic visualization tools much; instead, they are focusing on GIS software. It would seem that the reach of such software has moved beyond geographers and other social scientists into the heretofore less technologically well informed historical community. Apparently, many academic historians are now quite adept at using programs such as ArcGIS to meet their research and teaching needs. Researchers should confirm the true extent of this very significant shift in the historical community by developing additional questions about the technical knowledge of historians. Future research among archivists (and perhaps librarians) could deal with the broader question of how they approach the visualization of information objects and metadata, not just map interfaces specifically. Additionally, in this area of rapid change, future research among archivists could determine what has changed since the 2015 survey in terms of both attitudes and tools.

Simple tools such as Historypin are easy to learn and useful for archivists in connecting with local heritage groups. However, if archivists want to work closely with academic historians in documenting primary sources through maps, they would be wise to shift their focus to actual GIS software. To do so, archivists, especially those outside academia, will have to overcome the substantial technical and resource challenges and/ or collaborate with patron groups such as historians and historical geographers in the creation of such resources. More training opportunities should be available for archivists to learn about visualization/mapping tools and GIS software. Where feasible, archives should acquire these tools and work collaboratively with historians, geographers, and GIS specialists to fully exploit their utilities. Obviously, this will be easier to accomplish in academic environments with strong GIS programs. If even some of these things happen, visualization and mapping tools could be part of every archivist's technical toolkit in the near future. 


\section{ABOUT THE AUTHOR}

Tom Belton has an MA in public history from the University of Waterloo. He has been an archivist since 1988, and a certified archivist since 2005 .

Until 2001, he worked at the Archives of Ontario in a variety of roles. Between 2001 and 2004, he served as traveling archives advisor for the Archives Association of Ontario. Since 2005, he has worked at Western University Archives and Special Collections in London, Canada, with varying responsibilities including archives software administration, major photographic records holdings, and coordination of archives instruction.

Belton has written papers for the journals Archivaria and Libraries and the Cultural Record; most of these relate to the study of documentary forms in both organizational and personal contexts. His most recent article is "From Meteorological Registers to Climate Data: Information Gathering in the Early Years of the Meteorological Service of Canada," published in Archivaria, volume 69. He has presented at a number of conferences in Canada, the United States, and the United Kingdom. He is interested in alternative ways (including maps) of visualizing archival records.

\section{NOTES}

1. Esri, "About ArcGIS," and "QGIS: A Free and Open Geographic Information System," https:// www.qgis.org/en/site/index.html\#.

2. The Viewshare service was retired on March 20, 2018.

3. Library of Congress "Viewshare," https://labs.loc.gov/experiments/viewshare.

4. Shanti Interactive "Introducing VisualEyes 5," http://viseyes.org/visualeyes.

5. "Around the World and Back Again," Flicker Blog http://blog.flickr.net/en/2008/08/12/aroundthe-world-and-back-again.

6. Flickr, "The Commons," https://www.flickr.com/commons/institutions.

7. Historypin, "About," https://about.historypin.org/about.

8. C. Ahlberg and B. Shneiderman, "Visual Information Seeking: Tight Coupling of Dynamic Query filters with Starfield Displays," in Readings in Information Visualization: Using Vision to Think, ed. S. K. Card, J. D. Mackinlay, and B. Shneiderman (San Francisco: Academic Press, 1993), 313.

9. Mitchell Whitelaw “Generous Interfaces for Digital Cultural Collections," Digital Humanities Quarterly 9, no. 1 (2015), http://www.digitalhumanities.org/dhq/vol/9/1/000205/000205.html.

10. Ibid.

11. Paul Clough, Jiayu Tang, Mark M. Hall, and Amy Warner, "Linking Archival Data to Location: A Case Study at the UK National Archives," Aslib Proceedings 63, nos. 2-3 (2011), http://www .emeraldinsight.com/doi/abs/10.1108/00012531111135628.

12. Ibid.

13. Ibid., 132.

14. Deborah Boyer, "From Internet to iPhone: Providing Mobile Geographic Access to Philadelphia's Historic Photographs and Other Special Collections," The Reference Librarian 52, nos. 1-2 (2010): 47, http://www.tandfonline.com/doi/abs/10.1080/02763877.2011.521880.

15. Ibid., 48 . 
16. PhillyHistory.org, https://www.phillyhistory.org/PhotoArchive/Search.aspx.

17. Boyer, "From Internet to iPhone," 48.

18. Jefferson Bailey and Trevor Owens, "From Records to Data with Viewshare: An Argument, an Interface, A Design," Bulletin of the American Society for Information Science and Technology 38, no. 4 (2012): 41.

19. Ibid., 42.

20. Ibid., 43. Also, note that the Library of Congress retired Viewshare as of March 20, 2018.

21. Laura Deal, "Visualizing Digital Collections," Technical Services Quarterly 32, no. 1 (2015): 25, http://www.tandfonline.com/doi/abs/10.1080/07317131.2015.972871.

22. Craig Harkema and Catherine Nygren, "Historypin for Library Image Collections: New Modes of Access for Unique Materials at the University of Saskatchewan Library," Partnership: The Canadian Journal of Library and Information Practice and Research 7, no. 2 (2012): 1.

23. “Discovering Anzacs," National Archives of Australia, http://discoveringanzacs.naa.gov.au/browse/ places and https://web.archive.org/web/20140626100807/http://mappingouranzacs.naa.gov.au/ about.aspx.

24. Ibid.

25. Ibid.

26. Another example is the Brooklyn Historical Society's map layer for the finding aid of the Corporation Counsel records, http://brooklynhistory.org/library/wp/brooklyn-corporation-counselrecords-1843-1920.

27. "Search the Archives Catalogue and Online Collections," Dalhousie University, https://findingaids library.dal.ca.

28. Creighton Barrett, digital archivist at Dalhousie University Archives, provided the author with most of this information in a series of e-mails between October 5 and 26, 2017.

29. Library of Congress, "Encoded Archival Description Tag Library Version EAD3 1.1.0."

30. The subscribers to these listservs did not have to be members of these organizations. No promotion was undertaken on any of the more specialized listservs in the United States. The introduction invited archivists and special collections/manuscript librarians to respond.

31. Note: The author designed questions 2 and 3 to determine whether respondents were using mapbased interfaces to provide access to, or visualize, data. If the respondent answered "No" to both questions 2 and 3, he or she was given only three more questions (4 through 6) relating to patron groups that would benefit from map interfaces and the obstacles to their use in the respondent's institution. The survey thanked them for their participation. Questions 7 through 10 were only given to those who were using map-based interfaces.

32. Historical geographers are geographers who specialize in changes in spatial phenomena over time. Their methodology is similar to that of historians. 


\section{APPENDIX A: ARCHIVIST SURVEY QUESTIONS}

1. What type of archival or special collections institution do you represent?

2. Does your institution's online catalogue, descriptive database, or finding aid repository provide access to archival descriptions and/or digital objects (e.g. photographs) through a map interface?

3. Does your archives website provide any online visualizations of digital objects (e.g. exhibits of photographs or other graphic materials) via a map interface?

4. Regardless of how you answered question 3, to what extent do you think that your patrons benefit, or would benefit, from being able to visualize your holdings and/or search online catalogues or finding aids using a map interface? Check one.

5. Please identify which of your actual or potential patron groups that benefit, or would benefit, from being able to visualize your holdings and/or search online catalogues or finding aids using a map interface?

6. What are the main reasons that your institution does not provide visualizations of digital content via a map interface? Check all that apply.

7. What tools or web services are you using to visualize digital objects via a map interface? Check all that apply.

8. What sort of digital objects predominate in your map interface? Check all that apply.

9. What is the primary purpose of these online map interfaces for your institution?

10. Please make any additional comments that you feel are relevant. 


\section{APPENDIX B: HISTORIAN SURVEY QUESTIONS}

1. Please identify your discipline.

2. Please indicate your rank.

3. In what areas of research are you primarily focused?

4. What types of primary sources (i.e. usually created at the time under study) do you use in your research? Select all that apply.

5. What sorts of archives or libraries have you travelled to and/or researched extensively online in order to study primary sources? Select all that apply.

6. Please rate the tools (including online ones) that you use to find archival materials or other primary sources.

7. Please rate other methods that you use, or would you use, to locate archival records or other primary sources?

8. What sorts of research data do you accumulate as part of your research? Research data can be defined as any recorded material that you collect or generate as part of your research and that might be necessary to validate research findings. Select all that apply.

9. Which of the following best describes the formats of research data you generate or use in a typical research project? Select all that apply.

10. Which methods of sharing your research data do you currently use? Select all that apply. If you do not currently, or plan to, share your data, select "not sharing."

11. For the purposes of seeking primary or secondary sources, how would you rate the following methods?

12. How important is place-based or geospatial information to your research or teaching?

13. What types of geospatial information are important to your research or teaching?

14. In what way(s) do you, or would you like to, use geographic information or mapping software to capture and/or visualize data? Select all that apply.

15. Which of the following GIS software or mapping tools have you used?

16. What primary sources would lend themselves to discovery via an online map interface? Choose all that apply.

17. Do you have any additional comments or feedback? 